\title{
The link between symptoms of office building occupants and in-office air pollution: the Indoor Air Pollution Index
}

\begin{abstract}
The lack of an effective indoor air quality (IAQ) metric causes communication concerns among building tenants (the public), building managers (decision-makers), and IAQ investigators (engineers). The Indoor Air Pollution Index (IAPI) is developed for office buildings to bridge this communication discord. The index, simple and easily understood, employs the range of pollutant concentrations and concentrations in the subject building to estimate a unitless single number, the IAPI, between 0 (lowest pollution level and best IAQ) and ten (highest pollution level and worst IAQ). The index provides a relative measure of indoor air pollution for office buildings and ranks office indoor air pollution relative to the index distribution of the US office building population. Furthermore, the index associates well with occupant symptoms, percentage of occupants with persistent symptoms. A tree-structured method is utilized in conjunction with the arithmetic mean as the aggregation function. The hierarchical structure of the method renders not only one index value, but also several sub-index values that are critical in the study of an office air environment. The use of the IAPI for IAQ management is illustrated with an example. The decomposition of the index leads to the ranking of sampled pollutants by their relative contribution to the index and the identification of dominant pollutant(s). This information can be applied to design an effective strategy for reducing in-office air pollution.
\end{abstract}

\section{S. C. Sofuoglu', D. J. Moschandreas ${ }^{2}$}

'Department of Environmental Engineering, Suleyman Demirel University, Isparta, Turkey, ${ }^{2}$ Department of Chemical and Environmental Engineering, Illinois Institute of Technology, Chicago, IL, USA

Key words: Indoor air pollution; Office buildings; Occupant symptoms; Index formulation; Environmental management.

\section{J. Moschandreas,}

Department of Chemical and Environmental Engineering, Illinois Institute of Technology, 10 West 33rd Street, Chicago, IL 60616, USA

Tel.: (312) 567-3532

Fax: (312) 567-8874

e-mail: djm@it.edu

Received for review 25 February 2001

Accepted for publication 10 January 2002.

(C) Indoor Air (2003)

\section{Practical Implications}

To be truly relevant environmental indices satisfy three criteria, indices must promote communication among all shareholders including non-scientists, relate with effects, and qualify as tools of environmental management. This paper develops the Indoor Air Pollution Index (IAPI) and demonstrates that the IAPI satisfies the three criteria in an office environment. Consequently, the IAPI can be easily communicated to occupants, associates with occupant symptoms, and may be used as a practical tool for reducing in-office air pollution effectively.

\section{Introduction}

The plethora of environmental scientific papers, regulatory policies, and control strategies has not satisfied the public, the regulator, or the control engineer. The public does not comprehend the magnitude of the problem and trends related to environmental quality degradation or improvement. The regulator is faced with the difficulty of understanding and communicating complex scientific information and the control designer does not fully understand the problem and frequently addresses the wrong issue. Environmental scientists have not devised a quantitative method that unifies the qualitative concepts of measuring all envi- ronmental components. Clearly, all environmental objectives cannot be expressed in mere numbers, yet on certain occasions the formulation of a number indicator is appropriate and may assist in determining the present environmental status and suggesting environmental endpoints. We assert that this is the case for office buildings and that a metric of in-office air pollution can be used to rank office buildings according to their indoor air pollution levels and to assist in determining air pollution control strategies. The formulation of such a metric or index is the subject of this paper.

An index is constructed from several indicators weighted together to describe the total impact on a 
certain aspect of the broader state of the environment (Afsen and Saebo 1993). In an environmental context, Ott (1978) defines an environmental index as a single number aggregated mathematically from two or more 'environmental' indicators, where an indicator is a single quantity derived from one pollutant variable. Specifically, the use of individual pollutant concentrations in office buildings does not communicate effectively to occupants the state of the indoor environment they occupy because there are many pollutants, a few with high concentrations and many with low concentrations. Additionally, the relative scale by which high or low concentrations are expressed is different for each pollutant. Finally, there are no indoor air standards, or official demarcation levels against which occupants can compare the observed pollutant levels. The aggregation process from indicators to the index simplifies the complexity of the issue at hand and forms the link between the scientific community and the public and decision-makers because indices communicate the state of the environment in terms that the public can comprehend easily.

An indoor air index should associate with occupant health symptoms because pollution is known to be one of the main reasons for occupant complaints. Concentrations of single pollutants have not been shown to consistently associate with symptoms in observational studies. Although there is not a consistently used definition, total volatile organic compounds (TVOC) usually refers to "the sum of the mass concentrations of individual VOCs excluding very volatile and highly reactive compounds like formaldehyde' (Hodgson 1995) and has been measured and used as an indicator of indoor air quality (IAQ). However, studies that attempt to associate occupant symptoms and TVOC levels report inconsistent findings. While Skov et al. (1990a) found no significant associations between TVOC and occupant symptoms, Norback et al. (1990) and Hodgson et al. (1991, 1992) reported positive associations and Sundell et al. (1993) reported a negative relationship. Molhave and Clausen (1996) recommended consideration of TVOC as an indicator of IAQ. The inconsistency in association is also encountered in the literature for other individual pollutants. Armstrong et al. (1989) reported positive association between occupant symptoms and total suspended particles (TSP) but no other pollutants, and Hodgson and Collopy (1990) and Hodgson et al. (1991) found association with respirable suspended particles (RSP) but no other pollutants. Furthermore, other studies reported symptom associations to mineral fibers (Hedge et al., 1993) and to gram-negative bacteria (Teeuw et al., 1994). These conflicting associations in the literature inspired our investigation for an index of indoor air pollution. Such an index combines several indoor air pollutants and is more likely to associate with occupant symptoms because, in accord- ance with the premise of this study, in-office occupant symptoms relate with exposure to indoor air pollution rather than with exposure to individual pollutants.

Indices have been developed extensively for ambient air pollution (Babcock, 1970, Bisselle et al., 1972, Fensterstock et al., 1969, Green, 1966, Inhaber, 1974, Miller, 1973, MURC, 1968, Rich, 1967, Shenfeld, 1970, Swamee and Tyagi, 1999, Thom and Ott, 1976, Thomas et al., 1971), and for water pollution (Brown et al., 1970, Dinius, 1972, Horton, 1965, Prati et al., 1971, Walski and Parker, 1974). However, environmental indices are not widely used for indoor air pollution studies (Lahallec, 1995, Sekhar et al., 1999). Sekhar et al. (2000) reported that the Indoor Pollutant Standard Index (IPSI) (Sekhar et al., 1999), does not associate with occupant symptoms. The Index of Air Quality (Lahallec, 1995) had limited application because its potential association with occupant symptoms was not investigated. In addition to these aggregated indices, there are perception-based indicators of indoor air pollution that measure perceived rather than measured indoor pollution levels; such indices include the Olf \& Decipol (Fanger, 1988a, 1988b), Decibel (Jok1, 1995), and comprehensive percentage dissatisfied (Shi and Tao, 1996). Although these perception-based indices are applied in indoor air evaluation studies, especially in Europe, Oseland et al. (1994) pointed out the theoretical and statistical limitations of the concept and its development.

This study is based on the premise that an in-office building pollution index is an appropriate metric of office indoor air pollution. The in-office building pollution index discussed in this paper is based on measured pollutant concentrations. It represents a synthesis of such measured concentrations and does not reflect a specific, usually the maximum, value of one selected pollutant. An indoor index must satisfy three criteria: it must be (1) associated with occupant symptoms, (2) easy to understand, and (3) easy to estimate. The office index discussed in this paper secures its practical value by ranking a subject building relative to other buildings based on the population distribution of office indices. Such ranking and a subsequent decomposition of the index may assist an environmental engineer to design efficient strategies for reducing in-office air pollution. The objective of this paper is to formulate the Indoor Air Pollution Index (IAPI) that is easy to understand, relates with occupant symptoms, and provides the basis for designing an efficient indoor air control strategy.

\section{Methods}

Formulation of the IAPI begins with identifying the database to be employed and the aggregation function 
to be used. These are applied in the formulation of the index model and in the development of the tree structure of the index. The tree structure is used for the decomposition of the index and determination of efficient control strategies in office buildings.

\section{The database}

Data from US Environmental Protection Agency (EPA) Building Assessment Survey and Evaluation (BASE) study (Girman et al., 1995, Womble et al., 1995) are used in this study. The BASE study concurrently measures pollutant concentrations and identifies office building occupant symptoms using self-administered questionnaires along with building characteristics. A total of 100 buildings will be investigated when the study is completed. An available 41-building database (BASE 1994-1996) is used in the development of the index. The buildings were randomly selected from predetermined geographic areas (climatic regions); complaint status was not a factor in the selection process. The goal of the BASE study is 'to define the status of existing building stock with respect to determinants of IAQ and occupant perceptions' (Womble et al., 1994). In order to achieve this goal, a protocol was developed, see the Standardized EPA Protocol for Characterizing Indoor Air Quality in Large Office Buildings (US EPA, 1994).

Selection of the appropriate pollutants and the appropriate number of pollutants from among those measured frequently in practice would enable the index to describe the in-office air pollution. The BASE study list of pertinent pollutants to be measured was the outcome of discussions among 40 IAQ. These experts were asked to identify key variables that need to be measured to characterize the office indoor air environment. The BASE experts identified eight pollutants: bacteria, carbon monoxide, carbon dioxide, formaldehyde, fungi, $\mathrm{PM}_{2.5}, \mathrm{PM}_{10}$, radon, and TVOC. In addition to the BASE study, the pertinent literature was reviewed by assessing 151 papers published between 1980 and 1998. This literature review showed that measurement of nitrogen dioxide is more frequent than radon. Nonetheless, the IAPI was developed using the EPA list because the BASE study performed a symptom survey for occupants of areas sampled during the performance of the BASE field study.

\section{Aggregation function}

There are four types of aggregation functions. The first is linear sum function in which the final index is obtained through a simple addition of subindex values, that is, values for the concentration of each pollutant. Babcock (1970) used linear sum as the aggregation function for an air pollution index. This function generates a final index that is directly influenced by the number of variables included, which makes the index difficult to compare with other indices that have a different number of variables. Another aggregation type is the maximum operator. Hunt et al. (1976), and Thom and Ott (1976) used this function in the formulation of the Pollutant Standard Index (PSI), which was proposed to be the nationally uniform air pollution index. Smith (1989) and Sekhar et al. (1999) also used the maximum operator for a water and indoor air index, respectively. The maximum operator is not suitable for the application of indices used for the comparison of alternatives because the final index can take the same value for different environmental conditions. Swamee and Tyagi (1999) suggested a new aggregation function for PSI claiming that maximum operator is not a suitable aggregation function because it fails to give a composite picture of air pollution. The function proposed by Swamee and Tyagi is a member of the second type of aggregation functions: non-linear means (also used by Bhargava, 1983, Walski and Parker, 1974). However, non-linear means, like linear sum, may have the problem of 'ambiguity'. Ambiguity occurs when the overall index reports 'poor' environmental quality when no subindex exhibits 'poor' environmental quality. The arithmetic mean, the last aggregation function type, is the most frequently used form of aggregation function (Brown et al., 1970, Fensterstock et al., 1969, Green, 1966, Horton, 1965, Prati et al., 1971, Steihart et al., 1982). The fact that arithmetic mean values level out extreme values makes this aggregation function inappropriate for indices aimed at identifing violation of standards. However, Barbiroli et al. (1992) assess the arithmetic mean as the best choice for an index that aims to evaluate the state of the environment. Ott (1978) also pointed out that the arithmetic mean is a better choice in cases where indices are used to compare alternatives. Therefore, the arithmetic mean was chosen as the aggregation function for the IAPI.

\section{The Indoor Air Pollution Index}

The following eight pollutants are included in the index formulation: bacteria, carbon monoxide, carbon dioxide, formaldehyde (HCHO), fungi, $\mathrm{PM}_{2.5}, \mathrm{PM}_{10}$, radon, and TVOC. A linear function is used to calculate the subindices. IAPI is a combined index because subindices are aggregated using arithmetic mean in conjunction with a tree-structured calculation method. No descriptor categories are defined for the index. Instead ranking of a building's pollution level (IAPI value) in the population distribution of index values will be used. The IAPI is calculated using the following model. 
The Indoor Air Pollution Index

$$
\begin{aligned}
\mathrm{IAPI}= & \frac{1}{I} \sum_{i=1}^{I} \frac{1}{J} \sum_{j=1}^{J} \frac{1}{K} \sum_{k=1}^{K} 10\left[1-\frac{C_{i, j, k}^{\max }-C_{i, j, k}^{\mathrm{obs}}}{C_{i, j, k}^{\max }-C_{i, j, k}^{\min }}\left(\frac{C_{i, j, k}^{\mathrm{dmc}}-C_{i, j, k}^{\mathrm{obs}}}{C_{i, j, k}^{\mathrm{dmc}}}\right)\right] \\
& \text { for } C^{\max }>C^{\text {obs }} \text { and } C^{\mathrm{dmc}}>C^{\mathrm{obs}}>C^{\mathrm{min}}
\end{aligned}
$$

where $I$ is the number of level-3 groups, $J$, the number of level-2 groups in each level-3 group, $K$, the number of level-1 pollutant variables in each level-2 group, max, measured maximum concentration, min, measured minimum concentration, dmc, demarcation concentration and obs, measured concentration in the subject building.

The index employs the range of pollutant concentrations found in the BASE study, a demarcation concentration (a standard or guideline value), and concentrations measured in the subject building to estimate a unitless single number, the IAPI, between 0 (lowest pollution level and best indoor air quality) and 10 (highest pollution level and worst indoor air quality). The index equation consists of four parts: aggregation, location, normalization, and weight factors. The aggregation term is the first part before the paranthesis where the arithmetic mean is calculated throughout the tree structure, the location term $\left[C^{\text {max }}-C^{\text {obs }}\right]$ determines the measured concentration's distance from the maximum concentration, this distance is normalized over the entire range by the normalization term $\left[C^{\mathrm{max}}-C^{\mathrm{min}}\right]$, and finally the weight term weighted by $\left[\left(C^{\mathrm{dmc}}-C^{\mathrm{obs}}\right) /\right.$ $\left.C^{\mathrm{dmc}}\right]$, before the aggregation. Index calculation constraints include the following: (1) when $C^{\max }$ is less than $C^{\text {obs }}$ the calculation is performed by assigning $C^{\text {obs }}$ with the maximum concentration in the location term and assigning $C^{\mathrm{obs}}$ with the demarcation concentration in the weight term $\left(C^{\text {obs }}=C^{\text {max }}\right.$ and $\left.C^{\text {obs }}=C^{\mathrm{dmc}}\right)$; (2) when $C^{\mathrm{dmc}}$ is less than $C^{\text {obs }}$ but $C^{\max }$ is greater than or equal to $C^{\text {obs }}$ then observed concentration is assigned with the value of demarcation concentration, $C^{\text {obs }}=$ $C^{\mathrm{dmc}}$ and (3) when $C^{\text {obs }}$ is less than $C^{\mathrm{min}}$ then $C^{\text {obs }}$ takes the value of $C^{\mathrm{min}}$.

Demarcation values used in the weight term represent standards, guidelines and suggestions of pollutant levels associated with health effects. In other words, weight of a pollutant is determined by its health effects through employment of health-based guideline values (Table 1). Concentration data were used to determine maximum and minimum concentration values for each pollutant. A distribution was fitted to the measured concentrations of each pollutant, and the fifth and 95th percentile values were used as minimum and maximum values in the index. Crystal Ball (Decisioneering Inc., 1998) software was used to fit the following distributions to each pollutant's concentration database: beta, exponential, extreme value, gamma, logistic, lognormal, normal, and Weibull. Parameters of the hypothesized distributions are estimated using the Maximum Likelihood Estimators (MLEs) method.
Table 1 Demarcation values for the IAPI

\begin{tabular}{lrl}
\hline Pollutant & Demarcation & Source \\
\hline Bacteria & $500 \mathrm{cfu} / \mathrm{m}^{3}$ & ECA (1993) \\
CO & $10 \mathrm{mg} / \mathrm{m}^{3}$ & WHO (2000) \\
Fungi & $500 \mathrm{cfu} / \mathrm{m}^{3}$ & WHO (1988); Health and Welfare Canada (1993) \\
$\mathrm{HCHO}$ & $60 \mu \mathrm{g} / \mathrm{m}^{3}$ & Health and Welfare Canada (1987) \\
$\mathrm{NO}_{2}$ & $480 \mu \mathrm{g} / \mathrm{m}^{3}$ & Health and Welfare Canada (1987) \\
$\mathrm{PM}_{10}$ & $150 \mu \mathrm{g} / \mathrm{m}^{3}$ & NAAOS, 1997 \\
$\mathrm{PM}_{2.5}$ & $40 \mu \mathrm{g} / \mathrm{m}^{3}$ & Health and Welfare Canada (1987); Norwegian \\
$\mathrm{TVOC}$ & Directorate of Health (1991) \\
\hline
\end{tabular}

Goodness-of-fit tests, chi-square, Kolmogorov-Smirnov, and Anderson-Darling were used for each distribution.

Monte-Carlo simulation was used to construct the distribution of the index. The index equation was simulated; probabilistic approximations were obtained through repetitive random calculation of the index equation. The simulation calculates the index value 10,000 times to form the probability distribution for the IAPI, by sampling from the assigned distributions of the eight pollutant variables included in the model. A correlation matrix was formulated to test the correlation coefficients of all pairs of pollutants used in the formulation of the index. The only relatively high correlation value was that between $\mathrm{PM}_{10}$ and $\mathrm{PM}_{2.5}$ with an $r$ of 0.78 . All other correlation coefficient values have $r$-values of less than 0.35 . Simulations were run accounting for the correlation between $\mathrm{PM}_{10}$ and $\mathrm{PM}_{2.5}$ and the resulting IAPI distribution was almost exactly the same and all conclusions reached in this paper did not change. The IAPI discussed in the remainder of this paper does not account for the relationship between the two pollutants because the index formulation is not a statistical correlative model and is not impacted by this fact.

Sensitivity analyses were also performed to determine the change in output of a model when data, assumptions, or simply the value of an input variable of the model was changed. When performed for all of the input variables of a model, results were used to rank the input variables by their contribution to the model output. Uncertainty in the output of the model represents sensitivity of the model to the input variable for which the analysis was performed. In this study, Crystal Ball software was used to perform sensitivity analysis. Simple and multiple linear regression were used to investigate pollutant concentration-symptom and index-symptom associations.

\section{Tree structure}

A simple tree-structured method, proposed for developing water and ambient air quality indices by Barbiroli et al. (1992), is employed, in conjunction 


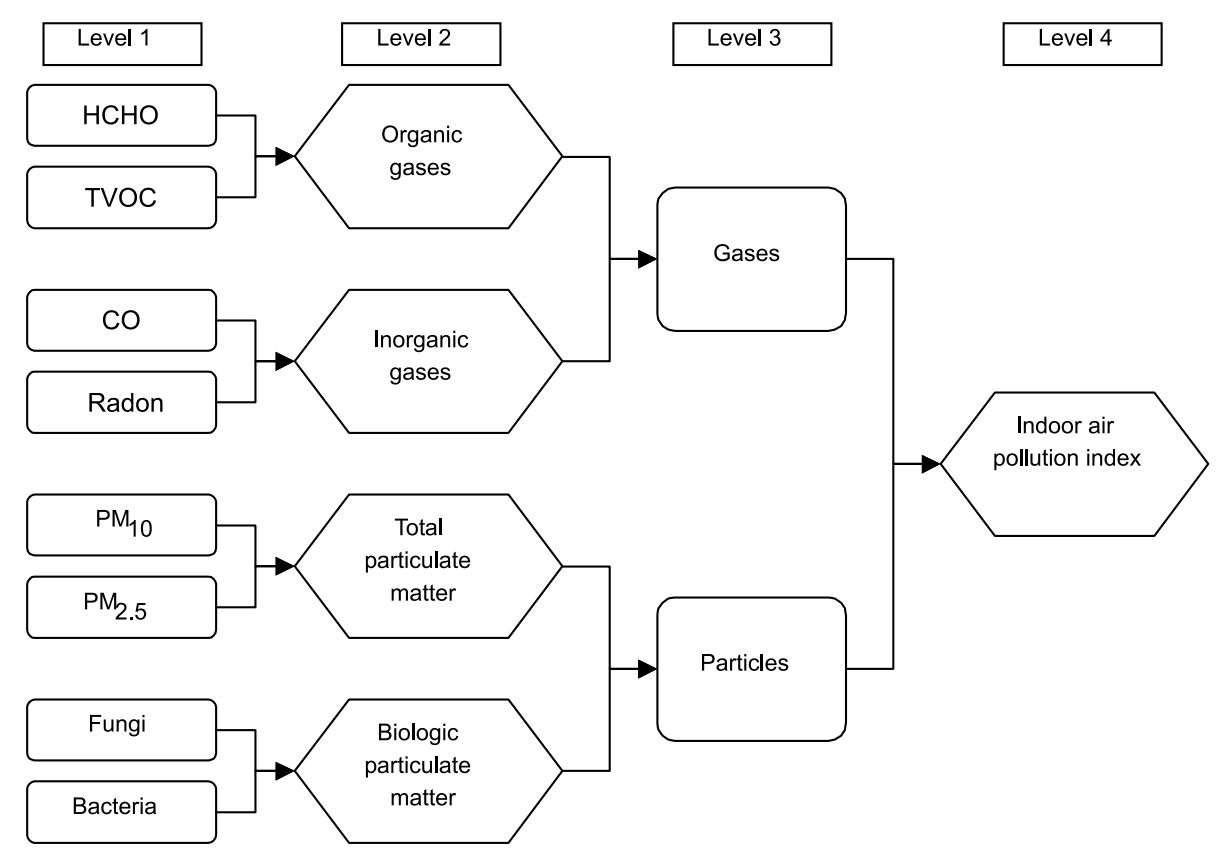

Fig. 1 Tree-Structured Aggregation for the Indoor Air Pollution Index

with the mean aggregation function in the calculation of IAPI. Thus, several intermediate indices are obtained on different aggregation levels before the IAPI is calculated. This feature of IAPI is unique because it has not been used to formulate indoor indices and because it enables the index user to estimate and rank the contribution of each pollutant to a building indoor air pollution by decomposing the index. Therefore, the index can be employed by IAQ practitioners to design efficient mitigation strategies focusing on the pollutant(s) with the highest contribution to the building indoor air pollution, which is essential for an optimal allocation of resources. The tree employed in the IAPI calculation is shown in Figure 1. The overall index is aggregated from two level-3 subindices for gases and particles. The subindex for gases is calculated by aggregating subindices of organic and inorganic gases of level-2. Level-3 subindex, particle subindex, is calculated by aggregating two level- 2 subindices, total particulate matter (TPM) and biological particulate matter (BPM) subindices. Level-2 subindices are the result of aggregation from corresponding level-1 subindices. Fungi and bacteria are aggregated to calculate BPM; $\mathrm{PM}_{10}$ and $\mathrm{PM}_{2.5}$ are aggregated to calculate TPM; $\mathrm{CO}$ and radon are aggregated to calculate inorganic gases; TVOC and HCHO are aggregated to calculate organic gas subindices. Each pollutant variable's level-1 subindex is calculated using the subindex function discussed in the previous section. In short, level-2 and level-3 subindices and the IAPI are obtained by aggregating the corresponding two indices of the lower level. Following the arrows, the IAPI is obtained hierarchically, starting on level-1 and ending on level-4. In addition to the overall index, IAPI, the indoor air pollution status of an office building may be assessed relative to the population of office buildings for level-1 pollutant variables, and level-2 and level-3 pollutant groups using intermediate indices. Thus, an indoor scientist will be able to present the relative state of the indoor air pollution with regard to six different pollutant groups, eight pollutants, and one overall index, the IAPI, for the building.

\section{Occupant symptoms}

Investigation of the IAPI - occupant symptom associations was performed using simple and multiple linear regression analyses. The BASE 1994-1996 buildings were grouped by using an index interval of 0.5 ( 1.5 to $<2,2$ to $<2.5,2.5$ to $<3$, and so on) thus providing 10 groups of IAPI values. The mean index and occupant symptom metric values were calculated for each group. The regression models were formulated using these mean values. A set of symptom metrics was used to study index-symptom relationships. These metrics are:

- Percentage of occupants with persistent symptoms (POPS). This indicator denotes the percentage of occupants in the sampled area of the office building persistently registering one or more symptoms.

- Maximum Occupant Symptom Score (MOSS). This indicator denotes the portion of the 19 symptoms registered in the symptom survey by the occupant in the sampling area who registered the largest number of persistent symptoms. 
- Building Symptom Index (BSI). This indicator denotes the average number of occupant symptoms in the sampling area (Burge et al., 1987).

Symptom metrics were calculated from the BASE 1994-1996 symptom survey, which posed the following question to the occupants of the office area sampled in the performance of the study. During the past 4 weeks you were at work, how often have you experienced each of the following symptoms while working in this building?

- Not in the last 4 weeks.

- 1-3 days in the last 4 weeks.

- 1-3 days per week in the last 4 weeks.

- Every or almost every workday.

The following symptoms were listed in the survey: dry eyes, wheezing, headache, sore throat, chest tightness, sinus infection, cough, tired eyes, tension, pain in the back, sneezing, feeling depressed, shortness of breath, difficulty concentrating, nausea, dry skin, fatigue, dizziness, and hand pain. It is important to note that all analyses in this study are based on occupants with 'persistent' symptoms.

The buildings were grouped according to their IAPI values, such as 0.5 to $<1.0,1$ to $<1.5$, and so on. The mean index and occupant symptom metric values (average of the metrics of each building in the IAPI group) were calculated for each group. Each symptom metric was modeled against the IAPI using simple linear regression. Coefficients of determination $\left(R^{2}\right)$ were used as a measure of the model adequacy because it measures the explained variation in the dependent variable by the independent variables used in the model; in addition the $P$-value of the $F$-statistic for the significance of the model is reported. The $95 \%$ confidence intervals for the mean and individual responses were also calculated. Residual analyses indicate that regression assumptions were satisfied.

\section{Results and discussion}

In addition to the statistical aspects of the index, this section addresses each of the three criteria that lead to a scientifically sound and practically useful index: ease of communication, association with occupant symptoms, and employment as an environmental management tool.

\section{Descriptive statistics}

Median, minimum, maximum, and several percentile values are listed in addition to mean values (Table 2). Fifth and 95th percentiles are included because these values are used as $C_{\max }$ and $C_{\min }$ in the index equation. Concentrations of nearly all pollutants are distributed lognormally. Only formaldehyde is Weibull and carbon monoxide and $\mathrm{PM}_{2.5}$ are gamma distributions. The BASE study identifies a sampling area in each building and samples were taken at three different sites in each sampling area. Mean values were assigned to the subject building to be used as the 'observed concentration' in the index equation. The index values for BASE 1994-1996 have a median of 3.7 and a mean of 3.9 (range: 1.7-6.2). The frequency histogram and cumulative distribution are shown in Figure 2. The best fitting distribution to the 41 index values is lognormal distribution with a mean of 3.9 and s.d. of 1.3 .

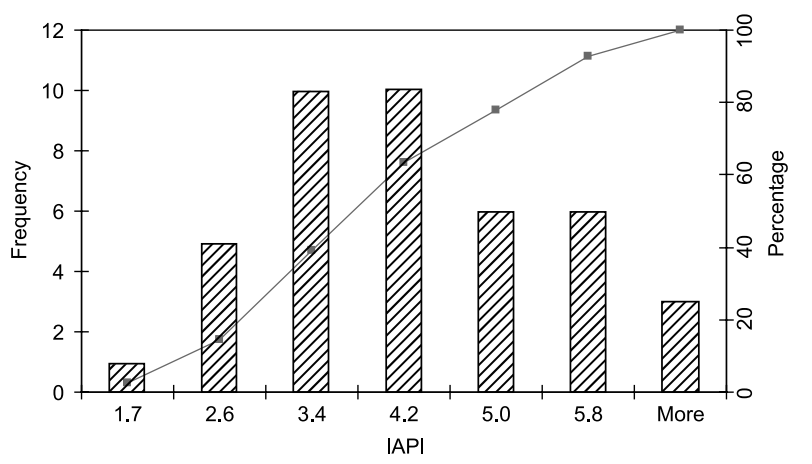

Fig. 2 Frequency and cumulative frequency histogram of IAPI for BASE' '94-'96

Table 2 Pollutant concentrations in BASE 1994-1996 buildings

\begin{tabular}{|c|c|c|c|c|c|c|c|c|c|}
\hline \multirow[b]{2}{*}{ Pollutant } & \multirow[b]{2}{*}{ Minimum } & \multirow[b]{2}{*}{ Maximum } & \multirow[b]{2}{*}{ Mean } & \multirow[b]{2}{*}{ Distribution } & \multicolumn{5}{|c|}{ Percentile } \\
\hline & & & & & Fifth & 50th & 75th & 90th & 95th \\
\hline Bacteria $\left(\mathrm{cfu} / \mathrm{m}^{3}\right)$ & 0 & 1081 & 59 & Lognormal & 1 & 20 & 77 & 261 & 539 \\
\hline $\mathrm{CO}\left(\mathrm{mg} / \mathrm{m}^{3}\right)$ & 0.0 & 10.5 & 2.5 & Gamma & 0.8 & 1.6 & 3.6 & 6.3 & 8.5 \\
\hline Fungi $\left(c f u / m^{3}\right)$ & 0 & 848 & 111 & Lognormal & 4 & 34 & 84 & 190 & 310 \\
\hline $\mathrm{HCHO}\left(\mu \mathrm{g} / \mathrm{m}^{3}\right)$ & 0.2 & 43.2 & 11.1 & Weibull & 0.7 & 7.1 & 13.3 & 21.0 & 26.7 \\
\hline $\mathrm{PM}_{2.5}\left(\mu \mathrm{g} / \mathrm{m}^{3}\right)$ & 1.3 & 41.2 & 12.4 & Gamma & 1.9 & 7.3 & 11.0 & 15.4 & 18.4 \\
\hline $\mathrm{PM}_{10}\left(\mu \mathrm{g} / \mathrm{m}^{3}\right)$ & 2.5 & 102.9 & 18.9 & Lognormal & 4.8 & 11.5 & 16.5 & 22.9 & 27.8 \\
\hline Radon (pCi/L) & 0.0 & 2.6 & 0.9 & Lognormal & 0.5 & 0.8 & 1.1 & 1.3 & 1.5 \\
\hline TVOC $\left(\mathrm{mg} / \mathrm{m}^{3}\right)$ & 0.04 & 19.1 & 1.6 & Lognormal & 0.4 & 1.4 & 2.5 & 4.3 & 5.8 \\
\hline
\end{tabular}

CO: carbon monoxide, $\mathrm{HCHO}$ : formaldehyde, TVOC: total volatile organic compounds. 
Table 3 Percentage change in IAPI with the number of pollutants employed

\begin{tabular}{lll}
\hline No. of pollutants & MPC in IAPI & $P$-value, WSRT \\
\hline 8 & - & - \\
7 & 17 & 0.00 \\
6 & 18 & 0.00 \\
5 & 22 & 0.00 \\
2 & 51 & 0.00 \\
\hline
\end{tabular}

MPC: median of percentage change in IAPI values for the 41 buildings WRT: Wilcoxon Signed-rank test.

Index and the number of pollutants required

The BASE study identifies eight pollutants as a requirement for characterizing in-office air quality. A deletion process simulates a likely inability of an investigator to measure all eight pollutants and estimates the effect on the index of measuring fewer than eight pollutants. The list of eight pollutants constitutes the base of comparison, and a specified number of pollutants (in groups of one or more) were deleted from the list to determine the effect of reducing pollutants measured. The percentage change in the IAPI value, for each of the 41 buildings, was calculated when the number of measured pollutants was reduced from eight to seven, and then to six, and so on. Pollutants removed were selected randomly; first $\mathrm{PM}_{10}$ was removed, followed by $\mathrm{CO}$ and radon, then $\mathrm{HCHO}$, $\mathrm{PM}_{2.5}$, and TVOC were removed as a group. The final group removed included all pollutants but formaldehyde and $\mathrm{PM}_{2.5}$. Median percentage changes in IAPI are shown in Table 3 along with test results for the null hypothesis of equal medians for the compared IAPI value sets. The median percentage change in the IAPI values for the 41 buildings was the lowest from the eight-pollutant set to the seven-pollutant set. The Wilcoxon rank test results show that the median values of the IAPI values for the full and reduced sets are significantly different. These results on the effect of number of pollutants employed in the model show that reducing the eight-pollutant list by only one pollutant significantly changes the distribution of the index. Additionally, these results demonstrate that employing different pollutants also affects the index values. Removing carbon monoxide and radon from the eight-pollutant-list caused almost the same amount of percentage change in the index values as when formaldehyde, $\mathrm{PM}_{2.5}$, and TVOC were removed, although the latter removed a larger number of pollutants compared with the former. These analyses show that the index is sensitive to pollutant variables.

\section{Sensitivity analysis}

The relative percentage of variance (RPV) in the index attributable to each pollutant variable was calculated
Table 4 Results of sensitivity analysis for the IAPI

\begin{tabular}{lcc}
\hline Pollutant variable & RCC & RPV (\%) \\
\hline CO & 0.37 & 19.2 \\
Formaldehyde & 0.35 & 17.2 \\
PM $_{10}$ & 0.32 & 14.0 \\
TVOC $_{\text {PM }}$ & 0.31 & 13.8 \\
Radon & 0.27 & 10.0 \\
Bacteria & 0.25 & 8.7 \\
Fungi & 0.25 & 8.6 \\
& 0.25 & 8.4 \\
\hline
\end{tabular}

RCC: rank correlation coefficient, RPV: relative percentage of variation.

to determine the relative importance of pollutant variables with respect to their effect on the index variation. The correlation coefficients for rank correlation between the IAPI and each pollutant variable were calculated. Higher correlation between an input variable (pollutant) and the output variable (the IAPI) point to higher impact of that input variable on the output compared to input variables with lower correlation. RPV values are calculated as squared rank correlation coefficients normalized against $100 \%$; Table 4 lists rank correlation coefficients and RPV values for each pollutant variable. The largest effect is from carbon monoxide, but all contribution percentages are close and no pollutant stands out (all RPVs are less than $50 \%$ ).

Another analysis for sensitivity quantified the relative change of the index value when only the concentration of one pollutant changed from its fifth percentile value to its 95 th percentile value, while the values of all other pollutants were kept at a constant concentration. The change in the index is the largest for TVOC and the lowest for $\mathrm{PM}_{2.5}$, with an average index change of one and a half unit.

Sensitivity analyses indicate that all pollutants have about the same effect on the index and that this effect is small for each contributing pollutant. This implies that a relatively large reduction in the concentration of one pollutant is required to reduce the index. But if one control strategy reduces concentrations of a group of pollutants, then the index reduction may be noticeable and may reach levels that noticeably reduce relevant occupant symptoms. One must always consider the possibility that the occupant symptoms may be associated pollutants not included in the index.

Index criterion I: the IAPI as a communication tool

The IAPI distribution for the US office building stock was estimated using Monte-Carlo simulations (Figures 3 and 4). The distribution is right skewed, mean and median values are 4.2 and 4.0 , respectively. Most of the index values $(90 \%)$ are less than or equal 


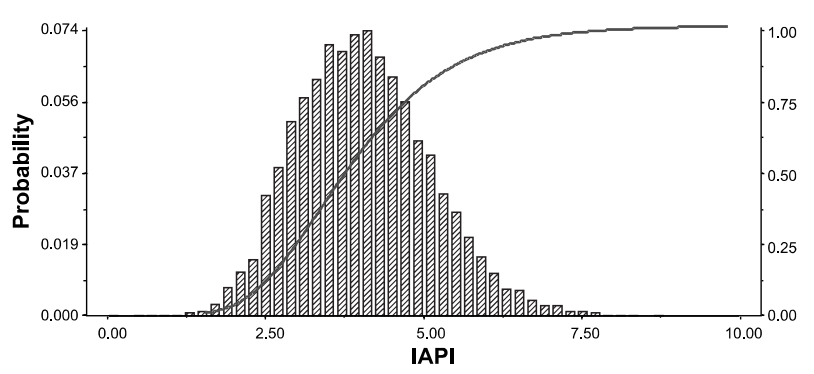

Fig. 3 Frequency distribution and fitted lognormal cumulative distribution $(\mu=4.2, \sigma=1.4)$ for simulated IAPI values
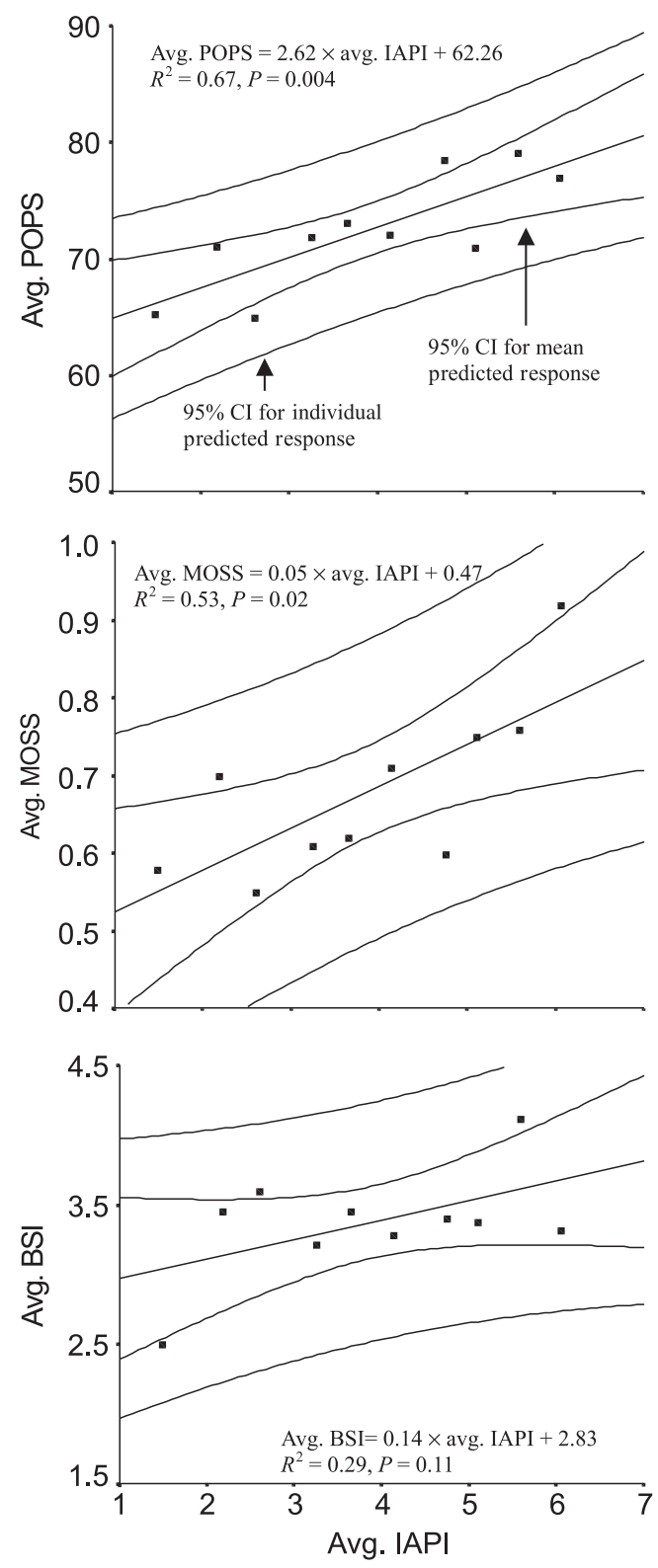

Fig. 4 Symptom Index - IAPI simple linear regression models

to 6.0. Lognormal is the best fitting distribution. The cumulative IAPI distribution may be used as a management tool that determines the status of the air pollution of an office building relative to that of the stock of office buildings in the USA. The percentile value of the distribution corresponding to a subject building's index value shows its ranking in the population. If a building has an index value of 5.5, on the average almost $80 \%$ of the office buildings in the USA have less pollution compared with the subject building. The use of the IAPI ranks in-office air pollution in the range of $0-10$, and the cumulative index distribution ranks the air pollution of a specific building under investigation relative to the population of buildings. These rankings furnish the indoor air specialists with two easy-to-understand tools and help bridge the communication discord that exists among environmental quality specialists and the public, occupants and decision-makers.

\section{Criterion II: The IAPI - occupant symptom associations}

Three linear regression models are formulated to associate the IAPI with occupant symptom indicators. First, each of the symptom indices (as the dependent variable) was associated with the index (as the independent variable). The adequacy of each regression model (Figure 4) associating symptom metrics with the IAPI was examined. The POPS model has an $R^{2}$ value of 0.67 and a $P$-value of 0.04 . The MOSS model features an $R^{2}$ value of 0.53 and a $P$-value of 0.02 . The BSI model $\left(R^{2}=0.29\right.$ and the $P$-value $\left.=0.11\right)$ is not significant at $\alpha=0.10$. Residual analysis indicates that the POPS and the MOSS models do not violate linear regression model assumptions.

One may think that symptoms should associate with the concentration of pollutants as well because the index is a function of pollutant concentrations. Hence, three symptom metric regression models were formulated for each pollutant, this time using concentration values for the IAPI values. Five of 24 models formulated are statistically significant at $\alpha=0.10$. The two largest $R^{2}$ values among the five models were 0.46 for $\mathrm{PM}_{2.5}$-POPS model and 0.45 for bacteria-MOSS model. Thus, the IAPI introduces an additional $21 \%$ variation explained with POPS and $8 \%$ with MOSS.

\section{Multiple linear regression models}

The effect of including one additional independent variable in the POPS model was investigated using the stepwise selection procedure for building age, occupant density in the sampling area, and floor area of the sampling area. The $R^{2}$ value was improved up to 0.68 when building age was the added variable. $R^{2}$ values were 0.69 and 0.68 when occupant density and floor area were the added variables, respectively. Nonetheless, partial $F$-tests indicate that none of the additions is significant. 


\section{Verification of the index-symptom model}

Focusing on a practical application of the index, we must assert that we are not seeking to establish a cause and effect relationship, rather we propose a potential practical tool for building management. As the index model association that explained the largest variation of the dependent variable was the POPS, we verify the model only with this symptom index. In the context of this paper model verification denotes evaluation of a regression model with data from an additional 12 buildings that were not used for the construction of the model. The IAPI and the three symptom metric values for the 12 buildings were calculated. The IAPI values were put in the respective regression models and each building's symptom index (POPS) value was estimated. The observed POPS values were compared with estimated values by formulating a simple linear regression model (see Figure 5). The 95\% CI of the individual predicted response is illustrated in this figure because the $95 \% \mathrm{CI}$ of the mean value is not applicable in this case. An analysis indicates that model estimations agree well with the observed values. Similar work was performed with the other indices but they did not perform as well. The MOSS model performance was anticipated because it is an individual's symptom metric rather than a building's symptom metric. The MOSS model represents the symptom score of the most sensitive person in a building - the person with the highest number of symptoms. However, POPS and BSI are building symptom metrics; hence, performance of these two metrics is better for model verification because the IAPI denotes a building's relative air pollution magnitude. The POPS model performed much better than the BSI.

\section{Criterion III: the IAPI as a management tool}

So far we have established that the index may be easily communicated to all shareholders of indoor air envi-

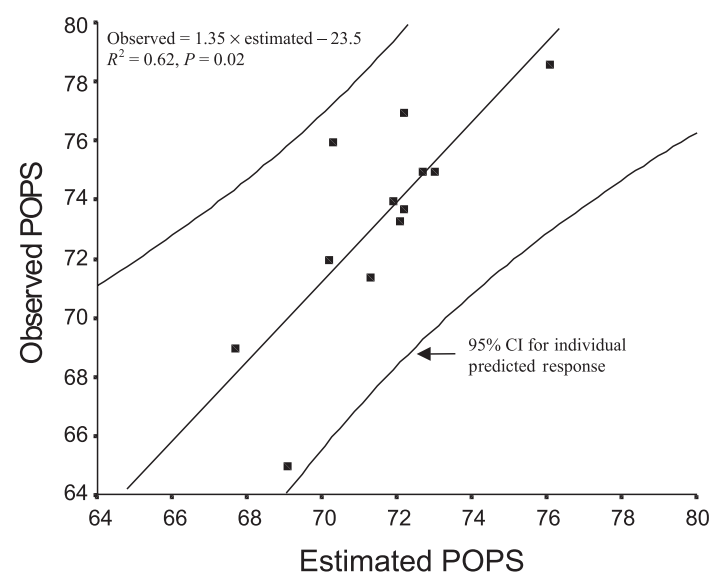

Fig. 5 Comparison and regression for observed and estimated POPS values using the 12 additional buildings ronmental quality and it associates with occupant symptoms. In this section we will elaborate on the process that employs the index as a management tool of indoor air pollution.

Building managers frequently seek alternatives to air sampling as the first step in the indoor air assessment process, because they realize that such a task is very expensive when implemented properly. The IAPI index becomes a management tool if it can be estimated inexpensively rather than measured. As the association between the IAPI and the occupant symptom POPS is given by a simple linear regression, we reverse the dependent-independent variables without loosing any of the strength of the association. Using the 41 buildings, we have formulated the following regression model between POPS and IAPI.

$$
[\text { Mean IAPI }]=0.25[\text { mean POPS }]-14.3
$$

While this procedure clearly reverses the dependentindependent variables in the regression model associating the IAPI index with the symptom metric, it does not affect the strength of the relationship between the two variables because the models used are simple linear models. The reversal is implemented because of its practical advantage: it is easier and less expensive to survey the occupants and estimate the IAPI than the other way round.

To verify this new model we use the 12 buildings not employed in the formulation of Equation 2 and compare the observed IAPI calculated with Equation 1 using pollutant concentrations of each of the buildings, with the estimated IAPI (see Figure 6). The model associating the IAPI and the symptom metric POPS, Equation 2, demonstrates that a large portion of in-office persistent symptoms is not associated with indoor air pollution as estimated by the IAPI. Indeed, when the IAPI takes the average value of 0 , the POPS

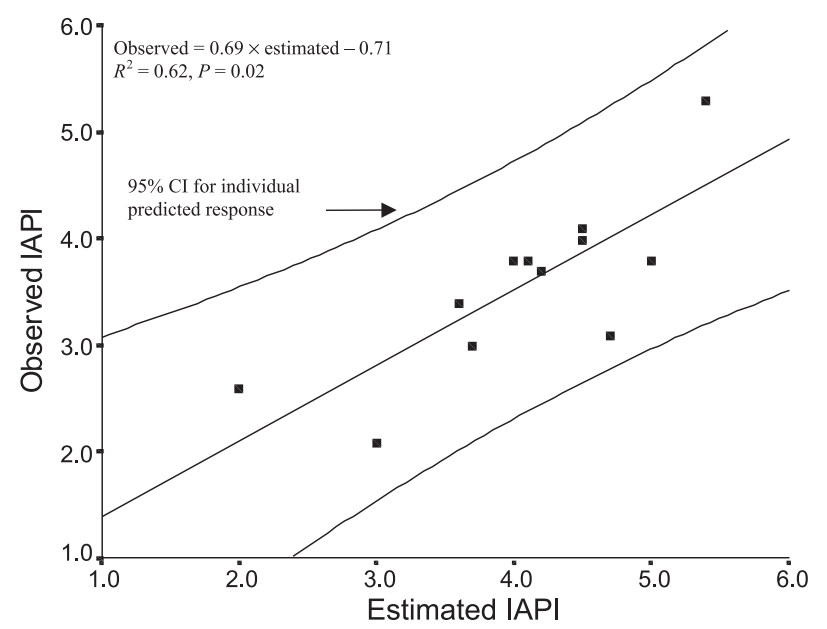

Fig. 6 Comparison and regression for observed and estimated IAPI values using the 12 additional buildings 
has an estimated average value of $57 \%$. This verifies a widely held assumption among indoor air pollution investigators.

This constrain notwithstanding, an indoor air assessment process of an office may begin when a building manager employs the BASE occupant symptom survey and estimates the building's IAPI value using the simple regression model developed in this study (see Equation 2). This value is then ranked relative to the IAPI population distribution. This constitutes the essence of the index as a management tool because it enables the manager to decide the next step to be implemented using the relative ranking of the building's indoor air pollution before any measurement. Moreover, the manager can justify her/his actions to the occupants as well as the owners. Now, if all agree that measurements are needed, a measuring experimental program will be designed and carried out. The IAPI values will be estimated using the index model and measured pollutant concentrations (see Equation 1). Decomposition will identify the contributing pollutants and lead to the most effective control strategies.

The sampling process, if necessary, would begin by designing a measurement program that measures the levels of all eight pollutants. Given these measurements, subindex and IAPI values will be calculated and the tree structure will be constructed. Then, contribution of each pollutant to the index is estimated by decomposing the IAPI.

An example of the index decomposition process is provided in Figure 7 for a building with a high index value. The comparison of level-3 indices of gases and particles (5.0 vs. 6.4) and percentage contributions to the higher level index $(44 \%$ vs. $56 \%)$ show that particles contribute more but the difference is not very large. The contribution of an intermediate sub-level index to the IAPI is the proportion of the sub-level intermediate index value in the sum of the index values of all groups in that sub-level. The comparison of level2 intermediate indices for gases shows a larger contribution is from inorganics $(25 \%)$ than organics $(19 \%)$. The comparison of level-2 intermediate indices for particles produces a clear lead with a $40 \%$ contribution from total particles compared with $16 \%$ from biological particles. Relative contributions for the four pollutants of the 'gases' group range from $0 \%$ for radon to $25 \%$ for carbon monoxide. The contribution of $\mathrm{PM}_{2.5}$ and $\mathrm{PM}_{10}$ accounts for $40 \%$ of the index. Therefore, we conclude that the building has a general problem with particulate matter. Indoor sources such as smoking or outdoor penetration and an inefficient filtering system may be some of the causes of this source of elevated index values. The highest contributing pollutant is carbon monoxide with $25 \%$. This pollutant also points to indoor combustion or outdoor air as potential sources. The decomposition may be employed to identify potential sources of indoor air pollution. The three dominant contributor pollutants are products of combustion or outdoor pollution. The IAQ manager now knows what sources and pollutants to focus on for his IAQ improvement strategy, if (s)he decides that improvement is needed. Note, the building manager can communicate with occupants easily by indicating that the present state of the building has a high index value (IAPI $=5.7)$ and that $82 \%$ of similar buildings have lower values of IAPI. The manager can further state that his/her objective may be to reduce the IAPI value to 4.2 ; that would mean that only $50 \%$ of office buildings have lower IAPI values. The manager

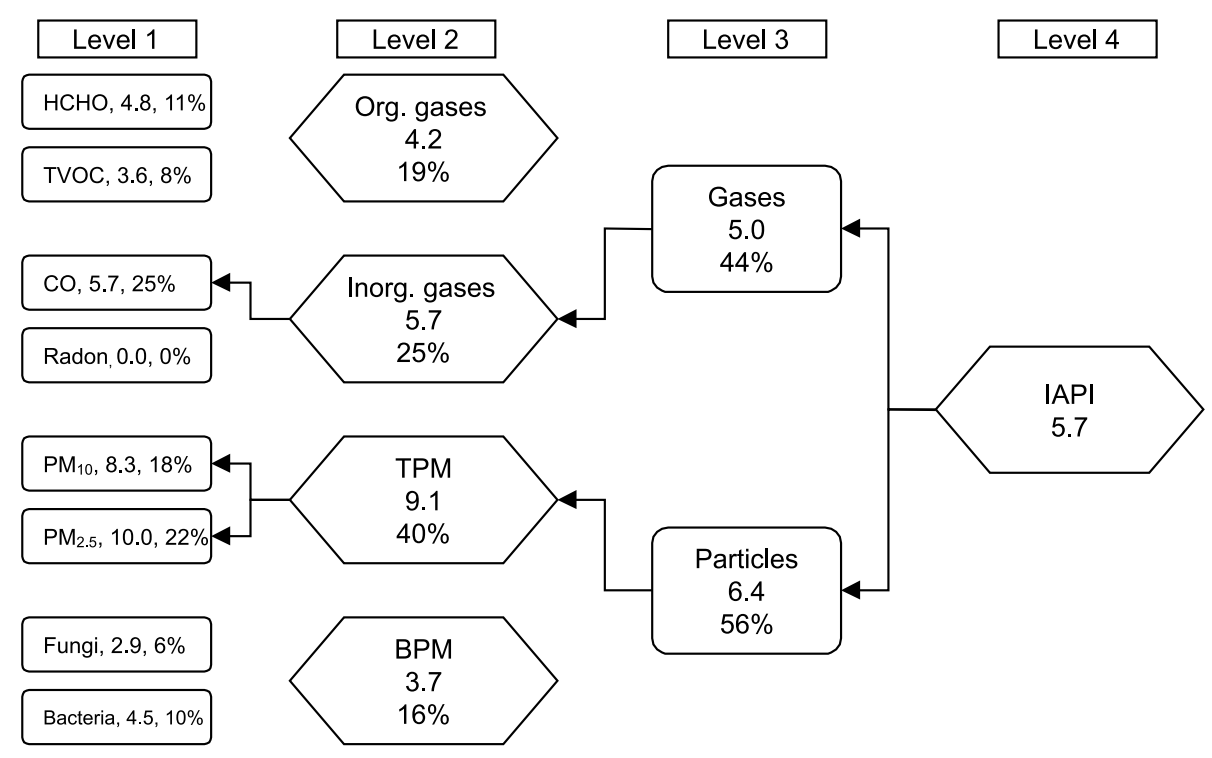

Fig. 7 An example for identifying major contributing pollutants 
can achieve this objective by reducing average concentration of the three dominant pollutants by $30 \%$. As a result, the POPS value of the building should reduce on average from 80 to $74 \%$, and the MOSS value should on average reduce from 0.86 to 0.71 . A $50 \%$ reduction in the IAPI would lead to a $16 \%$ reduction in the symptom metric.

\section{Conclusions}

An IAPI was formulated for the present study using the arithmetic mean as an aggregation function. The index satisfies the three criteria of environmental indices because it relates to occupant symptoms, it may be used as an environmental management tool, and it is easy to communicate to the consumer or non-specialist. The index developed in this paper is formulated on a portion of the BASE database, the final results may change when the total database is employed.

The IAPI associates well with office building occupant symptoms. The use of IAPI explained $67 \%$ of the variation in the POPS, as opposed to a maximum of $46 \%$ through the use of concentrations of individual pollutants. The index is sensitive to the number of pollutant variables employed and to the pollutants themselves. The associations were obtained using an eight-pollutant list, which was previously suggested by
40 IAQ experts for office buildings. It was further concluded that the index is sensitive to the pollutants that it utilizes; therefore, the complete list should be employed by all studies of indoor air pollution. The distribution of the index for the stock of US office buildings is lognormal, and the cumulative distribution is used to determine a building's pollution ranking relative to the US office building stock. The relative contributions of pollutants to a high index value can be estimated by decomposing the index through a tree structure. The sensitivity analysis showed that a relatively large reduction in the concentration of one pollutant is required to reduce the index, but if one control strategy reduces a group of pollutants, then the index reduction may be noticeable and may reach levels that noticeably reduce occupant symptoms. Therefore, the index enables building managers to focus their mitigation efforts on contributing pollutants where most needed for efficient allocation of resources. Furthermore, one may determine the level of required control on the identified pollutant(s) to achieve a better ranking in the US office building population. However, employment of the IAPI as a management tool must be guided by the fact that in-office occupant symptoms may be caused by factors other than exposure to air pollutants and managers must not promise more than this process can possibly deliver.

\section{References}

Afsen, K. and Saebo, H. (1993) Environmental quality indicators: background, principles, and examples from Norway, Environ Resour. Econ., 3, 415-435.

Armstrong, C.W., Sheretz, P.C. and Llewellyn, G.C. (1989) Sick building syndrome traced to excessive total suspended particulates (TSP). IAQ '89 The Human Equation: Health and Comfort, Atlanta, GA, ASHRAE.

Babcock, L.R. (1970) A combined pollution index for measurement of total air pollution, J. Air Pollut. Control Assoc., 20, 653-659.

Barbiroli, G., Mazzaracchio, P., Raggi, A. and Alliney, S. (1992) A proposal for a new method to develop synthetic quality indices for air and water, J. Environ. Manage., 36, 237-252.

Bhargava, D.S. (1983) Use of a water quality index for river classification and zoning of Ganga River, Environ. Pollut. (Ser. B), 6, 51-57.

Bisselle, C.C., Lubore, S.H. and Pikul, R.P. (1972) National Environmental Indices: Air Quality and Outdoor Recreation, Report No. MTR-6159, McLean, VA, MITRE Corporation.

Brown, R.M., McClelland, N.I., Deininger, R.A. and Tozer, R.G. (1970) A water quality index - do we dare? Water Sewage Works, 117, 339-343.
Burge P.S., Hedge A., Wilson S., Harris Bass J. and Robertson A.S. (1987) Sick building syndrome; a study of 4373 office workers, Ann. Occup. Hyg., 31, 493-504.

Decisioneering Inc. (1998) Crystal Ball v.4, Denver, CO, Decisioneering Inc.

Dinius, S.H. (1972) Social accounting system for evaluating water resources. Water Resou. Res., 8, 1159-1177.

ECA (1993) European Collaborative Action "Indoor Air Quality and its Impact on Man”. In: Biological Particles in Indoor Environments, Report No. 12, Luxembourg, Office for Official Publications of the European Communities.

Fanger, P.O. (1988a) Introduction of the olf and the decipol units to quantify air pollution perceived by humans indoor and outdoors, Energy Build., 12, 1-6.

Fanger, P.O. (1988b) The olf and decipol, ASHRAE J, 29, 35-38.

Fensterstock, J.C., Goodman, K., Duggan, G.M. and Baker, W.S. (1969) The development and utilization of an air quality index. In: 62nd Annual Meeting of the APCA, Paper No. 69-73, New York, NY.

Girman, J.R., Womble, S.E. and Ronca, E.L. (1995) Developing information on buildings and indoor air quality (BASE '94): Part II - environmental pollutant measurements and occupant perceptions.
In: Proceedings of Healthy Buildings '95, Vol. 3, Milan, 1311-1316.

Green, M. H. (1966) An air pollution index based on sulfur dioxide and smoke shade. J. Air Pollut. Control Assoc., 11, 703-706.

Hanna, S.R., Strimaitis, D. G., Chang, J.C. (1991) Evaluation of fourteen hazardous gas models with ammonia and hydrogen fluoride field data, J. Hazardous Mater., 26, 127-158.

Hanna, S.R., Chang, J.C., Strimaitis, D.G. (1993) Hazardous gas model evaluation with field observations, Atmos. Environ., 27A, 2265-2285.

Health and Welfare Canada (1987) Exposure Guidelines for Residential Indoor Air Quality, Ottawa, Canada, Department of National Health and Welfare.

Health and Welfare Canada (1993) Indoor Air Quality in Office Buildings: A Technical Guide, Ottawa, Canada, Department of National Health and Welfare.

Hedge, A., Erickson, W.A. and Rubin, G. (1993) Effects of man-made mineral fibers in settled dust on sick building syndrome in air conditioned offices. In: Proceedings of Indoor Air '93, Vol. 1, Helsinki, International Conference on Indoor Air Quality and Climate, 291-296.

Hodgson, M.J. and Collopy, P. (1990) Symptoms and the microenvironment in the sick building syndrome: a pilot study, 
In: Proceedings of IAQ'89 The Human Equation: Health and Comfort, Atlanta, ASHRAE, 8-16.

Hodgson, M.J., Frohlinger, J., Permar, E., Tidwell, C., Traven, N.D., Olenchock, S.A. and Karpf, M. (1991) Symptoms and microenvironmental measures in nonproblem buildings, J. Occup. Med., 33, 527-533.

Hodgson, A.T. (1995) A review and a limited comparison of methods for measuring total volatile organic compounds in indoor air, Indoor Air, 5, 247-257.

Hodgson, M.J., Muldoon, S., Collopy, P. and Oleson, B. (1992) Sick building syndrome symptoms, work stress, and environmental measures. In: Proceedings of ASHRAE IAQ'92 Conference, 47-56.

Horton, R.K. (1965) An index number rating system for rating water quality, $J$. Water Pollut. Control Federat., 37, 300-306.

Hunt, W.F. Jr, Ott, W.R., Moran, J., Smith, R., Thom, G., Berg, N. and Korb, B. (1976) Guideline for Public Reporting of Daily Air Quality-Pollutant Standards In$\operatorname{dex}(P S I)$, Publication No. EPA-450/276-013, Research Triangle Park, NC, Environmental Protection Agency.

Inhaber, H. (1974) A set of suggested air quality indices for canada, Atmos. Environ., 9, 353-364.

Jokl, M.V. (1995) Introduction of the decibel units to assess indoor air quality, In: Proceedings of 2nd International Conference of Indoor Air Quality Ventilation and Energy Conservation in Buildings, Montreal 1, 31-40.

Lahallec, C. (1995) An air quality index in the CLIM2000 software, In: Proceedings of the Healthy Buildings' 95 Conference, Vol. 3, 1709-1713.

MURC (1968) MURC index tells detroiters how dirty air is, Air Engin., 10, 28.

Miller, T.L. (1973) Short time averaging relationships to air quality standards (STARAQS) - a predictive air quality index model for use by air pollution agencies, In: 66th Annual Meeting of APCA, Paper No. 73-351, Chicago, IL.

Molhave, L. (1990) Volatile organic compounds, indoor air quality and health, In: Proceedings of Indoor Air '90, Vol. 5, Ottawa, International Conference on Indoor Air Quality and Climate, 15-33.

Molhave, L. and Clausen, G. (1996) The use of TVOC as an indicator in IAQ investigations, In: Proceedings of Indoor Air '96, Nagoya, International Conference on Indoor Air Quality and Climate, Vol. 2, $37-48$.
Norback, D., Torgen, M. and Edling, C. (1990) Volatile organic compounds, respirable dust, and personal factors related to prevalence and incidence of sick building syndrome in primary schools, $\mathrm{Br}$. J. Indust. Med., 47, 733-741.

Norwegian Directorate of Health (1991) Guidelines for indoor air quality, Norway, In: Maroni, M., Seifert, B. and Lindwall, T. (1995) (eds) Indoor Air Quality A Comprehensive Reference Book, Amsterdam, Elsevier.

Oseland, N.A., Aizlewood, C.E. and Raw, G.J. (1994) The new units of perceived air quality: where are we now? In: Proceedings of Healthy Buildings '94, Vol. 1, Budapest, 513-518.

Ott, W. R. (1978) Environmental Indices: Theory and Practice, Ann Arbor, Ann Arbor Science Publishers Inc.

Prati, L., Pavanello, R. and Pesarin, F. (1971) Assessment of surface water quality by a single index of pollution, Water Resour., 5, 741-751.

Rich, T.A. (1967) Air pollution studies aided by overall air pollution index, Environ. Sci. Technol., 1, 796-800.

Sekhar, S.C., Tham, K.W., Cheong, D. (1999) The development of an indoor pollutant standard index, In: Proceedings of Indoor Air '99, Vol. 2, Edinburgh, International Conference on Indoor Air Quality and Climate, 272-277.

Sekhar, S.C., Tham, K.W., Cheong, D. and Wong, N.H. (2000) A study of indoor air pollutant standard index (IPSI) and building symptom index (BSI), In: Proceedings of Healthy Buildings '00, Vol. 1, Espoo, 145-150.

Shenfeld, L. (1970) Note on Ontario's air pollution index and alert system, J. Air Pollut. Control Assoc., 20, 622.

Shi, M.H. and Tao, A.R. (1996) Investigation of the comfort evaluation index CPD of indoor environments, In: Proceedings of Indoor Air '96, Vol. 1, Nagoya, International Conference on Indoor Air Quality and Climate, 423-428.

Skov, P., Valbjorn, O. and DICS Group (1990b) The Danish Town Hall Study - a one-year follow-up, In: Proceedings of Indoor Air '90, Vol, Toronto, International Conference on Indoor Air Quality and Climate. 1, 787-791.

Skov, P., Valbjorn, O., Pedersen, B.V. and DICS Group (1990a) Influence of indoor climate on the sick building syndrome in an office environment. Scand. J. Work Environ. Health, 16, 363-371.
Smith, D.G. (1989) A new form of water quality index for rivers and streams, Water Sci. Technol., 21, 123-127.

Steihart, C., Schierow, L. and Sonzogni, W. (1982) An environmental quality index for the great lakes, Water Resour. Bull., 18, 1025-1031.

Sundell, J., Andersson, B., Andersson, K. and Lindvall, T. (1993) Volatile organic compounds in ventilating air in buildings at different sampling points in the buildings and their relationship with the prevalence of occupant symptoms, Indoor Air, 3, 82-93.

Swamee, P.K. and Tyagi, A. (1999) Formation of an air pollution index, J. Air Waste Manage. Assoc., 49, 88-91.

Teeuw, K.B. Vandenbroucke-Grauls, C.M.J.E. and Verhoef, J. (1994) Airborne gram-negative bacteria and endotoxin in sick building syndrome, Arch. Intern. Med., 154, 2339-2345.

Thom, G.C. and Ott, W.R. (1976) A proposed uniform air pollution index, Atmos. Environ., 10, 261-264.

Thomas, W.A., Babcock, L.R. and Shults, W.B. (1971) Oak Ridge Air Quality Index, Report No. ORNL-NSF-EP-8, Oak Ridge, TN, Oak Ridge National Laboratory.

US EPA (1994) A Standardized EPA Protocol for Characterizing Indoor Air in Large Office Buildings, Washington, DC, US Environmental Protection Agency.

US EPA (1997) National Ambient Air Quality Standards, Washington, DC, Office of Air Quality Planning and Standards, Environmental Protection Agency.

WHO (1988) Regional Publication Series, No. 31: Indoor Air Quality: Biological Contaminants, Report on a WHO Meeting, Copenhagen, World Health Organization.

WHO (2000) Guidelines for Air Quality, Geneva, World Health Organization.

Walski, T.M. and Parker, F.L. (1974) Consumers water quality index, J. Environ. Eng. Division, 100, 593-611.

Womble, S.E., Girman, J.R. and Highsmith, V.R. (1994) Collecting baseline information on indoor air quality. In $A S H R A E$ IAQ'94.

Womble, S.E., Girman, J.R., Ronca, E.L., Axelrad, R., Brightman, H.S., and McCarthy, J.F. (1995) Developing information on buildings and indoor air quality (BASE '94): Part I - study design, building selection, and building descriptions, In: Proceedings of Healthy Buildings '95, Milan, Vol. 3, 1305-1310. 